\title{
An Instructional Framework for Introducing Spatially Distributed Hydrologic Design Concepts
}

\author{
Joshua M. Peschel and Patricia K. Haan \\ Texas A\&M University, College Station, Texas 77843-2117
}

\section{Introduction}

Spatially distributed information technologies are emerging as an integral component of decision-making and design practices within the biological and agricultural engineering community (Mohtar and Engel, 2000; Ouyang and Barthoic, 2001; Choi et al., 2002). Several hydrologic and water quality models, such as the Soil and Water Assessment Tool (SWAT) (Di Luzio et al., 1997), the Better Assessment Science Integrating Point and Non-point Sources (BASINS) program (Di Luzio et al., 2002), the Automated Geospatial Watershed Assessment (AWGA) model (Miller et al., 2002), and the Hydrologic Engineering Center (HEC) software packages (USACE-HEC, 2000a; USACE-HEC, 2000b), are now constructed within geographical information system (GIS) frameworks. These types of GIS-based tools allow an engineer to better visualize problems and to design with spatially distributed data sets. With the increasing trends in availability and use of spatially distributed data, it is imperative that basic distributed modeling techniques be introduced to undergraduate students in a biological and agricultural engineering curriculum.

One of the core output parameters in any hydrologic or water quality model is surface runoff. Undergraduate students in biological and agricultural engineering are primarily taught traditional weighted average or "lumped" approaches to determine surface runoff in hydrologic-related problems. The often-standard procedure introduced for direct surface runoff calculation is the Natural Resources Conservation Service Curve Number (NRCS-CN) method (Chow et al., 1988; Haan et al., 1994; Gupta, 1995; Bedient and Huber, 2003). Originally developed in 1954 by the Soil Conservation Service (now known as NRCS) and later expanded upon, the NRCS-CN method is a time-averaged, direct runoff calculation that utilizes hydrologic soil group, land cover type and management practices, and antecedent moisture condition as input parameters (Rallison, 1980; Rallison and Miller, 1981; USDA-SCS, 1985 and 1986). The NRCS-CN basis parameters can easily be determined from publicly available digital spatial data sets using any standard GIS program (Melesse and Shih, 2002).

The pedagogical rationale associated with the NRCS-CN method is sound. Problems are more tractable and easier to solve by hand. However, the variability and orientation of spatial elements that may exist within a system of study motivates a distributed approach to problem solving. A simplified example is the construction of a suburban neighborhood (impervious surfaces) within a rural watershed. Given that flow calculations are based on soil type land cover, will there be a difference in the surface runoff calculation for the watershed that depends on the spatial location of the neighborhood? Using the traditional surface runoff calculation method, this question cannot be adequately answered. 
Undergraduate students may be introduced to spatially distributed techniques in later mathematical modeling or GIS courses, but there can often be a disconnect between hydrologic design concepts and new course content. Using a fundamental conservation of mass approach adapted from Moglen (2000), the NRCS-CN method can be employed to create simple one- and two-dimensional distributed hydrologic models. This can easily be integrated into a first-year hydrology course and may allow for a better understanding of distributed problem solving techniques in later undergraduate- and graduate-level engineering coursework.

\section{Objectives}

This paper presents the development of an instructional framework to assess student (learner) understanding of basic spatially distributed data sets and modeling within an undergraduate biological and agricultural engineering course at Texas A\&M University. The instructional framework presented is contained within six core domains, which may be categorically summarized as:

1. Learning Challenge and Learning Objectives

2. Authentic Scientific Inquiry

3. Embedded Information Technology

4. Assessment and Learning Products

5. Learning Experiences with Instructional Technologies

6. Strategic Planning for Implementation

The instructional material and techniques presented are to serve only as an informational precursor to later engineering hydrologic design coursework. It is not indented to replace currently accepted basic hydrologic design instructional methodology, rather is should supplement current practices. Spatial information technologies are now a reality in industrial and research projects concerning hydrologic and other environmental parameters. This work is intended to serve as a suggested bridge from traditional to spatially distributed decision-making and design practice instruction.

\section{NRCS-CN Calculation Procedures}

Though the focus of this article is an instructional framework, it is necessary to first briefly outline the steps in the NRCS-CN technique that will be used. For a more thorough treatment of the NRCS-CN procedure see USDA-SCS $(1985,1986)$.

The NRCS-CN method initializes with the calculation of the potential maximum retention of water after surface runoff begins. In the following expression:

$$
S=\frac{1000}{C N}-10
$$

$\mathrm{S}$ represents the potential maximum retention quantity (in inches) and $\mathrm{CN}$ is the value of the curve number. Equation (1) may also be viewed as representing the storage index. The range of the curve number parameter is $(0,100]$ and the exact value selected depends on the combination 
of hydrologic soil group and land surface characteristics for the area of study. Soils are categorized into one of four hydrologic groups (A, B, C, or D) and land surface characteristics are grouped by land cover and land use practices. Tables are available to cross-reference and obtain the value of the curve number once the soil and land surface characteristics have been identified (Chow et al., 1988; Haan et al., 1994; Gupta, 1995; Bedient and Huber, 2003). In the instructional framework, hydrologic soil group is determined using the Soil Survey Geographic (SSURGO) database (USDA, 1995; USDA-NRCS, 2001) and land cover is characterized by the National Land Cover Characterization (NLCD) database (USGS, 1992). Both are available in a digital spatial data set format.

Within the NRCS-CN method, an initial abstraction is assumed. Factors that are considered to contribute to the initial abstraction are natural interception, storage, and wetting. The standard assumption is $20 \%$ of the storage index:

$$
I=0.2 S
$$

where I is the initial abstraction (in inches). The surface runoff is finally determined from the following expression:

$$
Q=\frac{(P-I)^{2}}{(P+S-I)}=\frac{(P-0.2 S)^{2}}{(P+0.8 S)}
$$

where $\mathrm{Q}$ is the direct surface runoff (in inches) and $\mathrm{P}$ is the measured precipitation (in inches). Historical precipitation records are available from numerous sources. In this study, they are obtained from the National Oceanographic and Atmospheric Administration (NOAA). Finally, it should be noted that zero surface runoff occurs if the initial abstraction quantity exceeds the precipitation.

\section{Spatially Distributed Curve Number Approach}

Digital spatial data sets represent the landscape as a discrete collection of cells (or pixels) with individual physical properties such as soil type, land cover, and slope. Moglen (2000) used the NRCS-CN method to investigate the effects of curve number spatial orientation and distribution on surface runoff calculations within simulated and actual watersheds. Making the assumption that once precipitation is converted to surface runoff, it will proceed in the downhill slope direction, Moglen proposed the following expression based on Equation (3) for downhill surface runoff at a specific pixel location:

$$
R_{d}=\frac{\left[\left(\sum R_{u}+P\right)-I\right]^{2}}{\left(\sum R_{u}+P+S_{d}-I\right)}=\frac{\left[\left(\sum R_{u}+P\right)-0.2 S_{d}\right]^{2}}{\left(\sum R_{u}+P\right)+0.8 S_{d}}
$$

where $R_{d}$ is the surface runoff that leaves the downstream pixel into another pixel (in pixelinches), $R_{u}$ is the total summation of surface runoff from all immediately adjacent upstream pixels to the downstream pixel (in pixel-inches), and $\mathrm{S}_{\mathrm{d}}$ is the downstream pixel storage (in

pixel-inches). Precipitation is assumed to be uniform across each pixel. Slope and flow 
direction in the instructional framework are determined from Digital Elevation Model (DEM) files. Actual flow at the downstream pixel is determined by dividing Equation (4) by the total number of upstream pixels plus the downstream pixel:

$$
Q_{d}=\frac{R_{d}}{n}
$$

where $Q_{d}$ is the areal average surface runoff at the downstream pixel (in inches) and $n$ is the total number of pixels involved in the calculation. Figure 1 presents an illustrative example of Equation (4).

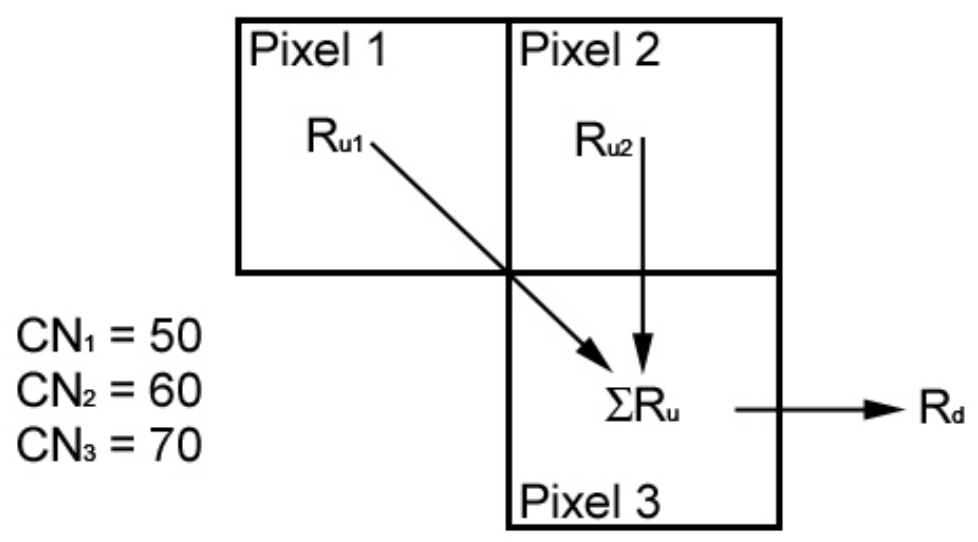

Figure 1. Illustration of Spatially Distributed Curve Number Approach.

Given that the precipitation is a uniform 5-inches across each pixel and that the curve numbers have been determined as shown in Figure 1, runoff values from pixels 1 and $2\left(R_{\mathrm{u} 1}\right.$ and $\left.R_{\mathrm{u} 2}\right)$ are calculated as 0.69-pixel-inches and 1.30-pixel-inches, respectively. The summation of the upstream pixel runoff, $\Sigma \mathrm{R}_{\mathrm{u}}$, is 1.99-pixel inches, therefore, the downstream pixel runoff, $\mathrm{R}_{\mathrm{d}}$, is found to be 3.61-pixel inches. Using Equation (5), the areal average surface runoff from the downstream pixel is 1.20-inches. With the basic distributed surface runoff equations established, one- and two-dimensional case examples can be developed.

\section{Instructional Framework}

\section{Learning Challenge and Learning Objectives}

As explained in the previous section, surface runoff calculations consist of two primary approaches: lumped and distributed. It is initially expected that learners will have been exposed to the lumped approach within the undergraduate engineering hydrology curriculum. The lumped approach to problem solving represents their current mental model, which is assumed to not include spatial thinking or consideration with respect to distributed problem solving. This assumption is based on the lack of exposure.

Creating a learning context where learners can develop a new and alternative spatially oriented mental model is the main idea behind the presented instructional framework. To assist 
in the development of the new and alternative spatially oriented mental model, the initial question is posed to the students: "To what extent does the orientation of spatially distributed curve numbers influence the runoff calculations within a watershed?" In the process of developing their own answers to this question, learners are exposed to new information technologies that allow them to critically evaluate limitations of the lumped approach by working with complex and spatially distributed data sets, such as soils and land cover from contemporary industry and research projects.

Comparison of the two surface runoff calculation approaches is immediately possible because techniques from the lumped approach are purposefully used in the development of the distributed approach. The learning objectives within this instructional framework are based on a subset of the ABET 2004-05 Criterion 3 specifications. These criteria are required components of any accredited engineering program in the United States. Specifically, the instructional framework addresses the development of critical and independent thinking, computer programming and engineering software exposure, and communication.

\section{Authentic Scientific Inquiry}

A modified authentic scientific inquiry procedure is derived from Chinn and Malhotra (2002) to be undertaken within the instructional framework. Learners will initially be given the research question as stated in the previous section. While traditional experimental procedures are not involved in the instructional framework, students will formulate a basic hypothesis with regard to the expectations of the lumped versus distributed surface runoff calculation results. Since the learners will be finding evidence for their own study areas using a formative assessment, observations will be made that may not have necessarily been found in the presented lab material.

Learners will be required to explain in a report what they have found in their formative assessments; questions will be generated as a result of the findings. Learners will additionally be responsible for finding inconsistencies within the digital spatial data sets. Some of the data sets may be incomplete in very subtle ways (missing values, etc.). This would noticeably modify the results and the learners will be expected to report this by examining the input data beforehand. Learners will compare all final product results after they are finished. This will be very convenient due to the final product being available on the course website. Indirect reasoning and generalizations will be formulated based on all of the final product results. Learners will then reflect on how what they reasoned now relates to their original hypothesis.

\section{Embedded Information Technology}

Learners will utilize four main categories of embedded information technology software: computation, visualization, presentation, and communication. These categories accommodate quantitative and qualitative aspects of learning.

ArcView GIS 3.2 by the Environmental Systems Research Institute (ESRI) is a GIS software program for computing and analyzing digital spatial data sets. This will likely be the learners' first exposure to a GIS software program, therefore practical skill development with this 
technology may be somewhat slow. Learners will be required to obtain and work with the actual land cover, soils, and historical precipitation records within ArcView GIS 3.2. Matlab Release 13 will also be used in the instructional framework for computation, but primarily for visualization. Available from The Mathworks, Matlab R13 is an advanced computer algebra system that allows users to perform tasks such as calculations, write and compile programs, and plot data. The learners will likely have had exposure to Matlab in prior classes and will use this package to plot the results of their 1-D and 2-D distributed surface runoff models.

Microsoft PowerPoint will be used by the learners to present the results and conclusions of their work. This also falls into the communication category in a verbal context. Microsoft FrontPage will be used communicate the learners' results and conclusions via the final product website. Effective written communication skills are an essential component of engineering practice. Learners will create their own feedback while working with the technologies. If they are able to successfully complete the modules, they will gain confidence using the technologies. This self-confidence is likely to promote further exploration of the capabilities within the embedded technologies themselves.

\section{Assessments and Learning Products}

The instructional sequence will take place over a five-week period. The instruction will take place within the course lab time, which is approximately 3-hours per week. Week 1 will allow learners to develop the necessary spatial visualization and manipulation skills using ArcView GIS 3.2. Learners will create basic maps of soil properties, elevation, and land uses. A formative assessment will be completed as an assignment to be due the next week. This assessment will provide feedback with respect to the learners' abilities to assemble and manipulate digital spatial data sets to arrive at some basic conclusions. Each learner will be required to submit three concept-related questions over the materials to the instructor within the next four days. These questions will be posted on the website and each learner will be required to answer 3 questions that are not their own. These will be turned in at the beginning of the next lab session and will provide feedback to both the learners and the instructor regarding the learners' understanding of the materials.

Week 2 consists of using Matlab R13 to develop, design, and visualize a simple 1-D distributed surface runoff model. A formative assessment will again be completed as an assignment due the next week. The second assessment will provide feedback with respect to the learners' abilities to understand fundamental conservation laws, apply the laws to a basic situation, and implement them in the form of a computer program. Learners will submit and answer another set of questions related to the topic of week 2 just like they did in week 1.

During the session of week 3, learners will use ArcView GIS 3.2 to formulate and implement a 2-D version of their distributed surface runoff models. A third formative assessment will be completed as an assignment due the next week. This assessment will provide feedback with respect to the learners' abilities to understand fundamental conservation laws, apply the laws to a basic 2-D situation, and implement in the form of a computer program within ArcView GIS 3.2.

Learners will submit and answer another set of questions related to the topic as in the prior two weeks. 
The final learning product, due two weeks after the third module is completed, consists of a presentation and project website that will contain a formal engineering report. The final product will be the summative assessment. The basis of the final product will essentially be represented by the knowledge and abilities developed within the three learning modules. Learners will select and request approval for their own area of study for the final product. Collaboration will be allowed to take place within the assessments of the three learning modules; however, the final learning product will be an individual effort.

\section{Learning Experiences with Instructional Technologies}

Instructional technologies within the framework are divided into two categories: instructor tools and learner tools. The instructor tools consist of Matlab R13 and Microsoft FrontPage. Matlab R13 will be used to create the series of instructional modules for the framework. These modules will help learners visualize distributed surface runoff calculation concepts. Microsoft FrontPage will be used to create a website for the learners to obtain all of the instructional materials related to the course. Prepared tutorials will assist the learners with better understanding the information technologies. Links to external website with related content and data repositories will be provided. One learner tool within the framework will be Microsoft PowerPoint. Learners will utilize this instructional technology as part of the final product. Presentation and communication of the learners' final products is an essential knowledgebuilding component (for later questioning) within the scientific inquiry process.

\section{Strategic Planning for Implementation}

First and foremost, it is essential that concepts within the instructional framework be congruent with the lecture content. A disconnect between the lecture and the lab materials may confuse learners and promote complacency towards the lab content, particularly since it will likely represent a smaller percentage of their course grade. Within the current working implementation plan, there are four components.

The first implementation task is for the instructor to develop a sufficient background in the scientific material to adequately provide the framework's science content. Gaining familiarity with the data and technologies involved may be necessary. Reserving the required resources is the next component of the strategic plan. Coordination is necessary with a computer systems manager or facility to ensure that lab space, computer resources, and the necessary software licenses are available to use when the course is taught. Making sure this is done early will be important due to limited lab space and times available. Preparation of all lab materials prior to the course being taught is the next implementation task. Finally, ensuring timely assessments and provide consistent feedback to learners is critical during the implementation process. Three formative assessments are undertaken during the framework. If the learners do not have an idea of how they are doing, it may create unwanted uncertainty within their learning experience. Further implementation tasks may be added to the strategic plan as the instructor of record continues to shape the course content. 


\section{Conclusions and Future Work}

This paper presents the development of an instructional framework to assess student understanding of spatially distributed data sets and technologies within a undergraduate biological and agricultural engineering hydrologic course. Results have not yet been determined since the instructional framework will not be implemented until the Spring 2004 academic semester. Instructional materials and ongoing results will be placed on the instructional framework website, located at http://baen.tamu.edu/users/josh/its. It is expected that at a minimum, learners will develop an awareness of spatially distributed data sets and modeling that will be encountered in later coursework.

\section{Literature Cited}

Chinn, C, and B. Malhotra. 2002. Epistemologically Authentic Scientific Reasoning in Schools: A Theoretical Framework for Evaluating Inquiry Tasks, Science Education. 86: 175-218.

Choi, J-.Y., B.A. Engel, and J. Harbor. 2002. GIS and Web-based DSS for Preliminary TMDL Development. In Proceedings of the Total Maximum Daily Load (TMDL) Environmental Regulatios Conference. Fort Worth, TX. pp. 477-484.

Di Luzio, M., R. Srinivasan, and J.G. Arnold. 1997. An Integrated User Interface for SWAT Using ArcView and AVENUE. American Society of Agricultural Engineers Annual Meeting. St. Joseph, M.I. Paper No. 97-2235.

Di Luzio, M., R. Srinivasan, and J.G. Arnold. 2002. Integration of Watershed Tools and SWAT Model into BASINS. Journal of the American Water Resources Association. 38(4): 11271141.

Gupta, R.S. 1995. Hydrology and Hydraulic Systems. Prospect Heights, IL: Waveland Press. pp. 98-105.

Haan, C.T., B.J. Barfield, and J.C. Hayes. 1994. Design Hydrology and Sedimentology for Small Catchments. New York, NY: Academic Press. pp. 63-67.

Melesse, A.M., and S.F. Shih. 2002. Spatially Distributed Storm Runoff Depth Estimation Using Landsat Images and GIS. Computers and Electronics in Agriculture. 37(1-3): 173-183.

Miller, S.N., D.J. Semmens, R.C. Miller, M. Hernandez, D.C. Goodrich, W.P. Miller, W.G. Kepner, and D.W. Ebert. 2002. GIS-based Hydrologic Modeling: The Automated Geospatial Watershed Assessment Tool. In Proceedings of the Second Federal Interagency Hydrologic Modeling Conference. Las Vegas, NV.

Mohtar, R.H., and B.A. Engel. 2000. WWW-Based Water Quality Modeling Systems to Enhance Student Learning. Journal of Engineering Education. 89(1): 89-94. 
Moglen, G.E. 2000. Effect of Orientation of Spatially Distributed Curve Numbers in Runoff Calculations. Journal of the American Water Resources Association. 36(6): 1391-1400.

Olivera, F., and D.R. Maidment. 2000. GIS tools for HMS Modeling Support. In Hydrologic and Hydraulic Modeling Support, eds. D.R. Maidment and D. Djokic. ESRI Press: Redlands, CA. pp. 84-98.

Ouyang, D., and J. Barthoic. 2001. Web-Based GIS Application for Soil Erosion Prediction. In Proceedings of the International Symposium on Soil Erosion Research. St. Joseph, MI. pp. 260-263.

Rallison, R.E. 1980. Origin and Evolution of the SCS Runoff Equation. American Society of Civil Engineers Symposium on Watershed Management. New York, NY. pp. 912-924.

Rallison, R.E., and N. Miller. 1981. Past, Present, and Future SCS Runoff Procedure. In Proceedings of the International Symposium on Rainfall-Runoff Modeling. Mississippi State University. pp. 353-364.

USACE-HEC (United States Army Corps of Engineers Hydrologic Engineering Center). 2000a. Geospatial Hydrologic Modeling Extension: HEC-GeoHMS. Davis, CA.

USACE-HEC (United States Army Corps of Engineers Hydrologic Engineering Center). 2000b. HEC-GeoRAS: An Extension Support of HEC-RAS Using ArcView. Davis, CA.

USDA (United States Department of Agriculture (USDA). 1995. Soil Survey Geographic (SSURGO) Database: Data Use Information. Miscellaneous Publication Number 1527, Washington DC.

USDA-NRCS (United States Department of Agriculture Natural Resources Conservation Service). 2001. National SSURGO Database Data Access. Available at: http://www.ftw.nrcs.usda.gov/ssur_data.html. Accessed 1 January 2004.

USDA-SCS (United States Department of Agriculture Soil Conservation Service). 1985. National Engineering Handbook. Section 4, Hydrology. Washington, DC.

USDA-SCS (United States Department of Agriculture Soil Conservation Service). 1986. Urban Hydrology for Small Watersheds. Technical Release 55. Washington, DC.

USGS (United States Geological Survey). 1992. National Land Cover Characterization. Available at: http://landcover.usgs.gov/natllandcover.asp. Accessed 1 January 2004.

\section{Biographical Information}


JOSHUA M. PESCHEL is an MS Candidate in Biological \& Agricultural Engineering at Texas A\&M University. He received a BS in Biological Systems Engineering in 2001, also from Texas A\&M. An Engineer-in-Training in the State of Texas, Peschel has been a research intern at the Naval Undersea Warfare Center in Newport, RI and at Andros Island, The Bahamas. His research interests include remote sensing, hydrology, and ecological engineering.

PATRICIA K. HAAN is an Assistant Professor of Biological \& Agricultural Engineering at Texas A\&M University. She received a Ph.D. in Biological \& Agricultural Engineering from North Carolina State University in 2000. Dr. Haan conducts research and teaches courses related to hydrologic and water quality modeling, ecological risk assessment, and TMDL monitoring. She is an editor of the textbook Statistical Methods in Hydrology. 